\title{
Learning outside the classroom - Flipping an Undergraduate Circuits Analy- sis Course
}

\section{Dr. Ronald H Rockland, New Jersey Institute of Technology}

Dr. Ronald H. Rockland received his B.S.E.E. and M.S.E.E. and Ph.D. in bioengineering and electrical engineering from New York University, and received an M.B.A. in marketing from the University of St. Thomas. After almost 25 years of industrial experience in research, engineering, marketing and sales management and general management with several high technology corporations, he joined New Jersey Institute of Technology (NJIT) in 1995 as an Assistant Professor. He is currently the chair and professor of the Department of Engineering Technology, with a joint appointment in the Department of Biomedical Engineering. Previous to that he served as Associate Dean, Undergraduate Studies for the Newark College of Engineering of NJIT. His research in industry was in the area of pacemakers and defibrillation, and his research at Medtronic Inc led to five patents. He was a principal investigator for a three year, $\$ 1$ million NSF grant entitled Medibotics: The merging of medicine, robotics and IT, and was a co-principal investigator for a $\$ 2.5$ million grant on pre-engineering workforce enhancement from the New Jersey Commission on Higher Education, as well as a principal investigator for a Whitaker Foundation grant. His current research is in biological signal processing, related to cardiovascular signals, and in enhancing STEM education through use of engineering principles. He has written over 50 articles in both journals and conference proceedings, in both the educational and biomedical fields. Dr. Rockland was the recipient in 2004 of the F.J. Berger award, a national engineering technology award presented by ASEE, and a 2000 award winner in Excellence in Teaching for NJIT, was named a Master Teacher in 2004, and was the chair of the Master Teacher's Committee. He is also very active in the Engineering Technology community, have served in numerous capacities for the Engineering Technology Division (ETD) of the American Society of Engineering Educators (ASEE), most recently as the Chair for ETD, as well as serving as a commissioner on the Technology Accreditation Commission (TAC) for ABET. He was selected in 2011 as a Fellow of the American Society of Engineering Educators.

\section{Linda Hirsch, New Jersey Institute of Technology \\ Ms. Levelle Burr-Alexander, New Jersey Institute of Technology \\ Dr. John D. Carpinelli, New Jersey Institute of Technology}

Dr. John D. Carpinelli is a professor of electrical and computer engineering and Executive Director of the Center for Pre-college Programs at the New Jersey Institute of Technology. He has served as coordinator of activities at NJIT for the Gateway Engineering Education Coalition and as a member of the Coalition's Governing Board. He previously chaired NJIT's Excellence in Teaching Awards Committee and is Past Chair of the University Master Teacher Committee.

\section{Dr. Howard S. Kimmel, New Jersey Institute of Technology}




\title{
Learning Outside the Classroom - Flipping an Undergraduate Circuits Analysis Course
}

\begin{abstract}
While the use of technology has increased in education, much of that technology, such as use of PowerPoint, SmartBoards and use of the Internet, has been used in the same pedagogical approach, which is lecture in the class, followed by homework outside of the classroom. While student engagement through active learning has been demonstrated to enhance learning, one of the challenges to faculty is how to include these active learning methods while still trying to cover sufficient material.
\end{abstract}

Over the last few years, the use of technology has opened up another instructional strategy, called flipping the classroom. In this strategy, students take on a greater responsibility for their learning, and lectures that would normally be given by the professor in the classroom are now available online. Therefore, the classroom time can be used to engage students in problem solving activities, while the professor acts more like a facilitator of learning rather than a lecturer.

In a four year Electrical and Computer Engineering Technology program, one of the sections of a junior level circuits course was converted to a flipped course as a beta test for this concept. Over the last few years, lectures in the course by the author have been converted into smaller learning objects, resulting in videos of less than 10 minutes. In many cases, a lesson may be comprised of 3-4 of these videos. The videos were created using Camtasia Relay, and uploaded to a Course Management System webpage (using Moodle), in a structured sequence. While many of these videos were created from previous PowerPoint slides developed by the author, many others were created using a specialized paper tablet called PAPERSHOW, which enables screen capture and video while writing on this tablet.

Over 50 videos were created for this course, and each week students were expected to review the videos related to the upcoming week's topics. Assessments were developed for learning outcomes for each week, along with assessments on the students' perception of the effectiveness on the video material.

This paper will describe the process of creating these videos, the structure of the course, and a summary of the assessments of both the student learning and the perceived effectiveness of this process. 


\section{Background}

Instructional delivery and the use of technology have changed over the years, from blackboard writing to the use of applications such as Blackboard for delivery of distance learning. Faculty need to identify effective strategies that could improve and strengthen academic programs in order to meet the learning needs of all students, especially the Net Generation students ${ }^{1}$. Recent advances, both in software, hardware and Internet delivery, allow a next generation of videos to enhance learning in the classroom.

However, with this new technology comes a need for a different pedagogical approach. Too often, faculty use some of the newer technologies to video their entire classroom lecture, with the idea that students will learn by viewing an hour or two worth of material. In many cases, these videos are in addition to traditional face to face (F2F) teaching. The problem, especially in a technical course, is that there is never enough time to complete all the material, as well as go over a sufficient number of examples to enable students to better understand the material covered in class. The other problem is that when you look at the Millennial students, their communication time is short. This generation of students grew up watching YouTube videos that were shorter than 10 minutes (changed two years ago to 15 minutes) and following Tweets that are 140 characters maximum. So this isn't a generation used to, or interested in, an hour video of lectures.

Recently, applications such as Camtasia ${ }^{\circledR}$ Relay have been used to "tape" lectures, by allowing the user to merge the video of PowerPoints and writing on tablets with the audio. However, rather than taping an entire classroom lectures, the author started to tape small 5-10 minute segments of a lecture, that are called learning objects. This is one of the changes in pedagogical approach.

A learning object was defined by The IEEE LTSC (IEEE Learning Standards Committee) as any entity, digital or non-digital, that may be used for learning, education or training. ${ }^{2}$ Learning objects are a new way of thinking about learning content. Traditionally, content comes in a several hour chunk. Learning objects are much smaller units of learning, typically ranging from 2 minutes to 15 minutes, and can be defined as "an independent and self-standing unit of learning content that is predisposed to reuse in multiple instructional contexts". ${ }^{3}$ L'Allier further refines this definition of a learning object as the smallest independent structural experience that contains an objective, a learning activity and an assessment. ${ }^{4}$

Learning objects, as a self-standing unit of learning, should include an objective, a learning activity, and an assessment ${ }^{5}$. The learning objects created for this course included the first two elements, with an additional example as a self-assessment.

Over the last three years, the author has developed the learning objects for a third year circuit measurement course for the Electrical and Computer Engineering Technology (ECET) program. This course has always been taught face to face, and the instructor had been teaching it for over 12 years. It consists of a one hour lecture and two hour laboratory, and typical topics in this course include Error Analysis, Ohm's, Kirchoff's Laws, Voltage and Current division, Independent and Dependent Sources, Mesh and Nodal Analysis, Thevenin/Norton, First Order 
Response and AC Steady State analysis. Over the last two years, 24 learning object videos were created.

\section{Flipping the classroom}

While the students were able to review the videos, there were two concerns that still existed that were not being addressed with technology:

1. That technology was not changing the way the author was delivering the information, nor was it helping to deliver additional information or cover extra problems.

2. While students were able to review the video, were they able to understand the materials?

One possible way to the first concern is a recent trend in education, called the "flipped" classroom $^{6}$. The concept of a flipped classroom is to have students view videos of the lectures as their homework, and utilize class time for in-class activities and problem solving. This can create more class time and not lose education time by having students take notes at home and do the work in class ${ }^{7}$. The other advantage of providing the lecture in this format is that students can review the videos several times. There will be a brief discussion in the results section as to addressing the second concern.

Over the previous two years, the author developed 24 learning object videos, as well as used Moodle as a Content Management System in his F2F class. Thus, the foundation for being able to flip this class existed, and an attempt was made to flip one of his Fall 2012 semester courses. The rest of the paper will describe his experiences as well as feedback from the students.

\section{Creating a flipped classroom}

In reviewing the concept of flipping the classroom, two things became apparent:

1. There was a need for additional videos. While the current 24 learning object videos included many of the topics that were covered in this class, not all were addressed by these videos. If the expectation of the students was to understand the material before class, then additional learning objects needed to be created.

2. With regard to the second point in the "Flipping the classroom" section, how was the author going to know if the students understood the material? The concept of flipping the classroom included the idea of working with the students in covering the traditionally assigned homework in class, so students' understanding of these videos were enhanced by problem solving. There was a need to assess student's knowledge prior to the class.

To address the first point, a total of 16 new videos were created. The first 24 videos were developed for this course using a combination of PowerPoint slides and Camtasia Relay. The average time to develop the concept and structure of each learning object, create the PowerPoint slides and develop the video using Camtasia Relay was between 2-4 hours. Many of the new videos would be a simulation of what the author would have presented in class, so a new technology, called PAPERSHOW ${ }^{8}$ was utilized in conjunction with Camtasia Relay.

PAPERSHOW, as the website states, is a digital writing solution that enables to instantly display handwritten notes from the paper to the screen. It utilizes an interactive paper, which detects the 
pen's movement, a Bluetooth ${ }^{\circledR}$ digital pen that captures the pen's position on the paper, and a Bluetooth ${ }^{\circledR}$ USB key, which stores the software and receives the coordinates of the pen's position. This system, which is very easy to carry in a computer case, enabled the additional recordings to be done in less than 1 hour. The author wrote on a paper the notes that were going to be recorded, and then utilized the PAPERSHOW system to capture this writing as video.

In addition to these videos, the author added weekly assessments. This was a required assignment, and had to be uploaded via Moodle before the class. These assessments were oriented to two areas - assessing the quality and usefulness of each learning object, via a multipart questionnaire, and the assessment of the learning outcomes for that week. There were nine course learning outcomes for this course. For each week (or in the case of multi-week modules, for each learning module), individual outcomes were developed, and assessed. These weekly/module learning outcomes were related to the overall course learning outcomes. Questions and problems were used to assess the students' success in developing the skills and knowledge specified by the learning outcome(s) that was related to the various learning objects.

For each week (or for each module) students had the ability to upload a "Reflection" document. This document, which was not a required assignment, enabled students to identify problems, concerns or positive results for the week's learning and assignments. The use of these "Reflection" documents was to identify to the author areas of concerns or questions by the students, so additional information could be developed. These indirect measures were combined with the direct measure of the learning outcome assessments and the indirect measures of the learning object questionnaire.

\section{Results}

In prior classes, there were some subject areas that were taught in-class, such as understanding learning styles, using advanced features of Word and Excel in a lab report, and presentation techniques, that were beneficial to the students but not required for the main subject material. Originally, time was taken during the lab portion of this course for these items Videos were created for these subject areas, enabling the author to provide a richer lab experience to these students. The latter two items were assessed through student work, both in the use of some of these features in a lab report, and a final presentation.

There were both positive and negative responses by the students to this material. Some of the comments of the students, from both the assessment of the learning objects and the reflection document, are as follows:

- This week I understood the learning object and I was able to do it without a problem. All the videos were of great help for me. I like the video because I can go over any time of the day and I don't have to worry about If I don't understand it. In fact all the videos were good and they are a great method of teaching.

- The video could have been helpful, however, this topic I felt was too brief

- The learning object was a good idea, because I have never worked with nodal analysis. I was able to pause the videos and reference the book to help me with solving the homework problems. 
Several of the negative comments dealt with a need for additional videos, which actually was a positive comment regarding how the students felt about the value of the videos. In Moodle, there is an ability to generate several different types of activity reports. In reviewing the activity on the key videos, most of these were viewed 2-3 times. This demonstrates the advantage of these videos, that students can review the material multiple times. Some of the videos relating to the use of Excel and Word were not viewed by everyone. This relates to prior knowledge that students bring to a class.

There were some negative comments, and as a result, the author had a 20 minute in-class discussion with the students at the mid-point of the semester, and asked them to be honest in evaluating the instructional strategy of flipping the classroom. The main points that were discussed were:

- The students liked the videos, and wanted more. The main reason they liked them was that they could refer back and review them.

- Students were very concerned about trying to do the learning outcome assessments, since they did not feel adequately prepared by reviewing the videos before class. All of the students viewed all learning object videos at least once, but only between $50-75 \%$ of the students completed the outcomes assessment for that learning object.

- Many students felt that by using the concept of flipping the classroom, the course was more a distance learning course and that is not what they wanted, nor did it fit their learning styles (one of the videos that were uploaded dealt with learning styles of students).

- Each learning object video contained one or two illustrative examples. In these videos, simple examples were used, so the students would be able to following the reasoning in obtaining a solution to the problems. However, students wanted to see more challenging problems.

As a result of these discussions, the author made three changes to the course. This is the process of continuous improvement within a course.

- Created a series of nine "Challenge Problems". These were problems different from the problems solved in the learning objects. The video would introduce the problem, and then ask students to press the Pause button, and solve the problem. Then the students could compare their method and final solution with the video. These videos were created using PAPERSHOW and Camtasia Relay.

- Initially, each assessment was paired with one or more video links in the Moodle page, and was below the video link. The author placed the video links at the top of each week's section, and placed all links for the assessments and reflection documents at the bottom of the week section. Students responded that they liked that type of separation between information and assignments.

- Modified the course from a "Flipped" course to a "Semi-Flipped" course.

What is meant by semi-flipping is that the videos are still available to the students before the lesson and the assessment on both the learning object and learning outcome is available to be completed and uploaded before the lesson. However, each topic is still covered in class, but in a different way - by introducing the topic by working on problems immediately. Since the 
background material is in the video, students do not need that material to be presented in class. If students are still uncertain about how to solve the problems by utilizing the discussed topic, they can refer to the video after class. Students are responsible to complete the assessment before the next class.

It is difficult with just one class to do a comparison with any increase in skills or knowledge. One skill that was increased over the previous year's course was related to one of the course learning outcomes - "Identify, in writing, the best circuit theory to apply to various resistive circuits to solve for voltage and current measurements", In the final exam, there was increase in the number of students (from six students to 12 students) from the previous year's final, who identified possible circuit theories to use, and then justified why they chose the specific law. The author believes this is due to the several challenge problems, which were created because of the flipping of the classroom, utilized this method. In addition, there was a six point increase in the average for the final between this year's class and the previous class. Both finals utilized similar questions, with the same degree of difficulty. This difference was not statistically significant.

\section{Conclusion and Plans for the Future}

One of the main advantages of attempting to "semi-flip" the classroom was to eliminate, from lab or class discussion, peripheral items that would be interesting, but not necessarily critical for the success of the course. Having the videos allowed the students to focus during the lecture, to listen to the material rather than write down detailed notes, since they knew they could review the material again from the videos.

The challenge problem videos were one of the favorite items in this course, based on the student assessments. Several of these problems were the same as covered in class, and because of the ability to review them at home, the students appreciated these challenge problems. Additional challenge problems were created that were not part of the classroom discussion. Too often, students listen in class to a professor working on a problem, have no idea what was done, and quickly forget how to do it. This is not the case when students, at their leisure, can review the problem.

The biggest challenge the author found in trying to implement a flipped classroom is to get students to work on the material before the class period. While it was a graded assignment, only $50-75 \%$ worked on the material. One incentive that might be implemented in a spring course, which the subject course in this paper is a prerequisite, would be to increase the portion of these assignments relative to the final grade. The author will also award extra credit if the assessments are done prior to class, and the expectation is that more students will complete the assessments before the next topic is covered in class.

The majority of the students that were part of this class will be part of a subsequent class in the spring semester. To determine whether they have obtained the necessary skills and knowledge from this prerequisite course, the author will be giving them a pretest during the first week of the spring course.

Flipping the classroom, or "semi-flipping" the classroom as was done by the author, is not something simple. Instructors should first start to look at their material, break them up into 
learning objects (with associate learning outcomes), create the videos, and then create the assessments. This is something that will take a considerable time, and should be done over several semesters, until instructors get a critical mass of videos for their course.

\section{Bibliography}

[1] Kyei-Blankson, Lydia; Keengwe, Jared; Blankson, Joseph, "Faculty Use and Integration of Technology in Higher Education", AACE Journal, v17 n3 p199-213 Jul 2009

[2] IEEE Learning Technology Standards Committee (LTSC) (2001) Draft Standard for Learning Object Metadata Version 6.1. http://ltsc.ieee.org/doc/

[3] Polsani, Pithamber R "Use and Abuse of Reusable Learning Objects", Journal of Digital Information, Vol 3, No 4 (2003)

[4] L'Allier, James J. (1997) Frame of Reference: NETg's Map to the Products, Their Structure and Core Beliefs. NetG http://www.netg.com/research/whitepapers/frameref.asp

[5] Cavus,Nadire, Ibrahim, Dogan, "Using Learning Objects to Teach Programming Languages", Proceedings of the Creating the Future 3rd FAE International Symposium, European University of Lefke (Nov 25-26, 2004, Lefke, Cyprus)

[6] Riendau, Diane, "Flipping the Classroom" The Physics Teacher -- November 2012 -- Volume 50, Issue 8, pp. 507

[7] Alvarez, Brenda, "Flipping the Classroom: Homework in Class, Lessons at Home", Education Digest, v77, n8, pp 18-21, April 2012

[8] http://www.papershow.com/us/ 